

\title{
Assessment of Structural Qualities of Production Systems
}

Ulf Bergmann, Matthias Heinicke

\section{To cite this version:}

Ulf Bergmann, Matthias Heinicke. Assessment of Structural Qualities of Production Systems. IFIP International Conference on Advances in Production Management Systems (APMS), Sep 2016, Iguassu Falls, Brazil. pp.317-324, 10.1007/978-3-319-51133-7_38 . hal-01615766

\section{HAL Id: hal-01615766 https://hal.inria.fr/hal-01615766}

Submitted on 12 Oct 2017

HAL is a multi-disciplinary open access archive for the deposit and dissemination of scientific research documents, whether they are published or not. The documents may come from teaching and research institutions in France or abroad, or from public or private research centers.
L'archive ouverte pluridisciplinaire HAL, est destinée au dépôt et à la diffusion de documents scientifiques de niveau recherche, publiés ou non, émanant des établissements d'enseignement et de recherche français ou étrangers, des laboratoires publics ou privés.

\section{(c)(1)}

Distributed under a Creative Commons Attribution| 4.0 International License 


\title{
Assessment of Structural Qualities of Production Systems
}

\author{
Ulf Bergmann and Matthias Heinicke* \\ Otto von Guericke University Magdeburg, Magdeburg, Germany \\ $*$ Matthias .heinicke@ovgu . de
}

\begin{abstract}
Turbulent changes of the production program challenge the suitability of the operating point of the production system. This can result in a lack of efficiency and productivity of a formerly mature configuration of a production system. In this case, the logistic positioning becomes obsolete. Therefore, a periodic monitoring of the system configuration is necessary to ensure a resilient production. To cope with those challenges, this paper introduces an approach which evaluates strategies in terms of adjusting the system configuration. On the one hand, this refers to control strategies influencing the temporal organization and thus the system's behavior. On the other hand, also a variation of the spatial organization in terms of the layout of the production system can be considered. For different production structures effects of changed production programs on the system configuration and its resilience is explained and adequate measures for adapting the temporal or spatial structure are appraisable.
\end{abstract}

Keywords: Temporal structure - Spatial structure - Operating point · Production system configuration · Resilience $\cdot$ Structural quality

\section{Introduction}

The production industry - mainly due to the globalization of sales and purchase markets - is faced with new kinds of general conditions, resulting in decreasing quantities of similar products and, at the same time, increasing numbers of customer-specific variations. A clear change is noticeable, from multi-variant large-scale production towards customer-specific batch production, which comes as a result of this very individualization of the customers' demands. This often leads to short-cycle adjustments within the factory and production structure, since mastering these types of production largely depends on the implemented system structure. As for the operating routine, there is no objectively measurable parameter to verify the appropriateness of the installed system structure: The Structural Quality, the development of which is currently undertaken by several research activities at the Otto von Guericke University in Magdeburg. 


\section{Scientific Background}

A system is regarded as an entity of elements, the interrelations existing between these elements and the respective characteristics of these very elements and interrelations. Based on the production-technical approach, a factory can be defined as a production site providing an efficient manufacturing of goods. Production in this context is the system itself as the location where the actual manufacturing takes place [1]. In principle, production systems are socio-technical systems, since during the manufacturing process the elements of the technical subsystem (machines and plants) together with the elements of the social subsystem (people) enable the internal production process [2]. In order to simplify the structural approach for these kinds of production systems, the subcomponents of the technical and social system will be regarded as the smallest system units in form of work systems [3].

As a matter of fact, production systems exist - as any field of known matter - in space and time and are classified; thus, they do possess a structure in terms of a certain organization of the system (System Configuration). Based on the system-specific type and number of system elements (System Composition), a structure describes the basic order of a system (System Setup) depending on the existing system interrelations. As a result, it determines the function of the system (System Behavior). The System Setup is, therefore, determined by the existing System Composition, i.e. the type and number of all system elements, depending on the type, orientation and intensity of the system-inherent, physical interrelations between the system elements. This preferably economical arrangement of system elements for implementing the processing sequences is called Spatial Structure [4]. The System Behavior is characterized by the type, number and order of any kinds of processes that might be implemented through the functional linking of the system elements (processing sequences). The chronological structuring of the processes into segments and their timely interaction is called Temporal Structure [1]. In the context of manufacturing and assembly systems, resilience is the ability of the system to cope with changes of all sorts [5]. This concept refers to the System Behavior and the System Setup in terms of both, rapidly and flexibly reconfiguring the operating states of a production system or enduring to changes due to the preservation of a stable system configuration [6]. In particular, the property called robustness that allows a system to maintain its functions despite external and internal perturbations [7], is important due to an adequate response to turbulent market and customer changes.

Analytical approaches for checking or evaluating an installed system structure are contrasted by design approaches to pre-determine flexible system structures in the context of factory and production structure planning. Deficits in such structure configurations are mainly provoked by the mostly one-sided observation of the spatial aspects of structuring (before Start-of-production - SOP), since the temporal component will usually only be determined by the time sequence of the production processes (after the real SOP) [8,9]. Only the temporal dependency of type, number, linking and arrangement of the system elements is considered with the help of dynamic structuring approaches [10]. A fact of- 
ten ignored is that, besides the arrangement of the system elements, it is also the manner of their interactions which defines an entire system structure. Therefore, an evaluation of the structure's appropriateness is necessary which considers both the spatial and the temporal aspects of production structures. Following the previous remarks, the evaluation of the Structural Quality should be based on the System Setup as well as the System Behavior.

\section{Model for Structural Evaluation}

\subsection{System Setup - Basic Considerations}

The setup of a production system mainly depends on the System Composition and is reflected in the plant layout as regards the Spatial Structure. Consequently, the System Setup should be understood as function of the System Composition and the concrete Spatial Structure (Equation 1):

$$
\text { System Setup }=f(\text { System Composition; Spatial Structure })
$$

These determinations usually occur during the planning stage of a production system, starting with the definition of the type of operational means and the technologies on which they are based. In a next step, this will provide the system-specific level of concentration or the differentiation of the working steps, respectively, leading eventually to the level of task distribution that is possible during the system's operation. In order to guarantee the required capacitive performance of the system-specific means, its number will be determined at last. After this functional determination and dimensioning, the next step of structuring is to work out an ideal Spatial Structure. Existing procedures may optimize such a spatial arrangement, usually by minimizing the length of present transport routes between the individual operational systems (Equation 2). Thus, the focus is mainly set on optimizing the material flow $[8,9]$.

$$
\sum_{i=1}^{m} \sum_{j=1}^{m} l_{i j} \cdot D_{i j} \Rightarrow \min
$$

$l_{i j} \quad$ Intensity between object $\mathrm{i}$ and object $\mathrm{j}$

$\mathrm{D}_{i j} \quad$ Distance between object $\mathrm{i}$ and object $\mathrm{j}$

m Number of objects

\subsection{System Behavior - Basic Considerations}

The concrete behavior of a production system will only become transparent during operation. Therefore, the System Behavior is based on the System Setup defined before and causally influenced by the selection of the Temporal Structure. Accordingly, the System Behavior can be understood as function of the System Setup and the selected Temporal Structure (Equation 3):

$$
\text { System Behavior }=f(\text { System Setup } ; \text { Temporal Structure })
$$


Previous methods for evaluating the operational quality of a production structure mainly focus on three parameters in this respect: throughput time, output rate and the work in progress (WIP). Completing this by adherence to delivery dates, we will have all the figures for the so-called logistic performance indicators. These are usually visualized in form of operating curves, thus locating the current operating point of a production system multi-dimensionally [9]. Based on the operating curve, a theoretical optimum for running a production structure can be determined. In this context, the WIP features a double role as control variable and evaluating parameter and is used as an assessment tool. Accordingly, the WIP in the production system is the only parameter that is directly influenceable by the activities of production planning and production controlling - which during the operation of a production structure have a big impact on determining their System Behavior - and immediately affects the remaining logistic performance indicators. Therefore, the individual objectives must be weighed up against each other in order to achieve an adequate picture of the present operational target system. As for the strategic focus of an enterprise, hierarchic target systems are common practice and are also used when projecting production systems. However, when operating such elaborated production systems, the focus is mostly set on the logistic performance indicators. Here, the quality of the System Behavior, which is mainly determined by the System Setup, is evaluated and, in the next step, the quality of the system structure is assessed by using operating curves.

Moreover, specific versions of the characteristic curves depend on different conditions for the respective production system (e.g. the integration of operating systems into the material flow), i.e. the comparability of operating points depends on the respective aspects of the production structure [11]. Basically, the characteristic of a production program for a concrete production system influences the System Composition as well as the Spatial and Temporal Structure. Except for the production program, all factors can be directly influenced by the enterprise. While in case of an identical Spatial Structure, the operating points of a system might be compared for different Temporal Structures, e.g. with changed controlling processes, it is not easy to make a reverse assessment with the help of the logistic performance indicators. This is due to the fact that changing the Spatial Structure often induces a change in the resource basis as regards the System Composition. Only with unchanged type and number of system elements, a consistent basis for evaluation is guaranteed. Otherwise, the different dimensioning and/or a changed functional scope of individual resource elements distort the comparison's significance. In order to compensate for this deficit, it is required to normalize the parameters. Thus, a normalized presentation of the logistic performance indicators is required to be able to draw conclusions which are largely independent from the system-specific conditions [11].

\subsection{Main Findings - The Structural Quality}

In order to assess the quality of a present production structure it is necessary to determine adequate reference values for the normalization. For the output rate 
and the WIP it is advisable to relate these values to the ideal operating point, thus expressing them as relative values. If the maximum output rate is set on $100 \%$, then the medium output rate can be directly converted and interpreted as medium utilization. For the WIP it is advisable to normalize with the ideal minimum WIP as reference point. The resulting relative WIP indicates to which degree the absolute WIP of a production system deviates from the ideal minimum WIP. If the ideal minimum WIP and the maximum utilization are set on 100\% respectively, the normalized output rate operating curve will be the result. A relative measure for the throughput time or the range respectively is the flow rate. If the mean WIP is set in relation to the output rate, the weighted flow rate will be obtained as normalized value for the operating range [11].

As a result of this normalization, the calculation equations for the utilization, the relative WIP and the weighted flow rate do not include the specific order (production program) and direct capacity figures (system composition) any longer. Resulting normalized operating curves are therefore mainly systemindependent, focusing exclusively on the Spatial and Temporal structure of the observed production system.

Accordingly, the Structural Quality of production systems can be seen as vector of the quality of the Spatial and Temporal structure (Equation 4):

$$
\overrightarrow{S Q}=\left(\frac{S Q_{\text {spatial }}}{S Q_{\text {temporal }}}\right)
$$

where,

$\overrightarrow{S Q} \quad$ Structural Quality

$\mathrm{SQ}_{\text {spatial }}$ Spatial Structural Quality

SQtemporal Temporal Structural Quality

\section{Application Scenario}

\subsection{Use Case and Results}

Basically, the Structural Quality provides the planner with a number to evaluate an implemented production structure. Moreover, the Structural Quality may also serve as a planning index when reconfiguring an observed production structure. Such a reconfiguration is based on changing general conditions (mainly the change of the production program) as well as on changes of system-inherent characteristics: this refers to the System's Composition, Setup and Behavior.

Figures 1 and 2 illustrate the way the Structural Quality is applied as key number by using a typical manufacturing system of the metal processing industry as an example. Produced are shaft, gearing and housing components with machine tools applying different operation sequences, respectively. The implemented production structure is arranged in an operation-oriented setup (workshop structure), with a levelled dispatching of the manufacturing orders being provided by a standardized production program. At first the characteristic curve was plotted by using a discrete variation of the production program in terms of 
an order load on a percentage basis in order to evaluate the temporal structure. Thus, the load of the production system as measured by the WIP was modified stepwise. As a result, a reasonable curve regarding the lead time and the output rate depending on the respective WIP arose. Moreover, the transport effort of the spatial structure was calculated according to Equation 2. The optimal Spatial Structure relates to an ideal arrangement of machines. Due to layout constraints arising from the real circumstances of the building, the attained spatial quality amounts to 1,75 (percentage compared to the optimal material flow).

Subsequently, the numbers for normalization were computed. The ideal minimum WIP amount in a workload of about 2500 hours. The maximum output rate considered the capacity of the entire system, i.e. the sum of the capacity of all particular work systems. It amounts 448 hours per working day. The theoretical minimum throughput time is the sum of all net process times. In this ideally consideration absolutely no transition or waiting time occurs. The normalized values for each operation point (level of WIP) can be calculated on the basis of these numbers (minimum throughput time, ideal minimum WIP, maximum output rate). For this purpose, the percentage gap between achieved and ideal value are arithmetically averaged and yield the figure for the temporal quality. According to the definitions of Structural Quality, the spatial and temporal vec-

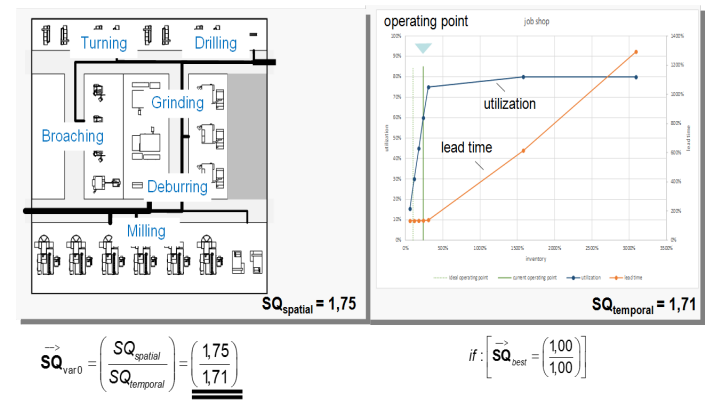

Fig. 1. Structural Quality of a manufacturing system (as-is state)

tor components for this workshop structure result in the values 1,75 (normalized transport effort) and 1,71 (normalized operating point), combined in the column vector Structural Quality (Figure 1, Equation 4). Thus, the Structural Quality enables to check a potential variation within the System Setup.

In the given example occurs an object-oriented reconfiguration of the spatial arrangement (line structure). Here, various products share a specific production line and in this context certain resources which are necessary to produce the respective products. All together the products are allocated to three different production lines. Neither the production program nor the System Composition (in type and number of the operating systems) are subjected to any changes in this respect and remain fixed. The System Behavior (in form of dispatching and controlling the manufacturing orders) is altered first into a reorder point pro- 
cedure (variant 1) and subsequently into a Kanban principle (variant 2). Thus, this results in a variation of the Spatial and Temporal Structure. Again, characteristic curves for the new production structures were plotted. The numeric values for the normalization are equal to the first calculation. The numbers for the spatial and temporal vector components, now with the values 1,40 (normalized transport effort) and 4,60 (normalized operating point of the reorder point procedure) or 3,41 (Kanban principle), are combined again in the column vector Structural Quality (Figure 2, Equation 4).

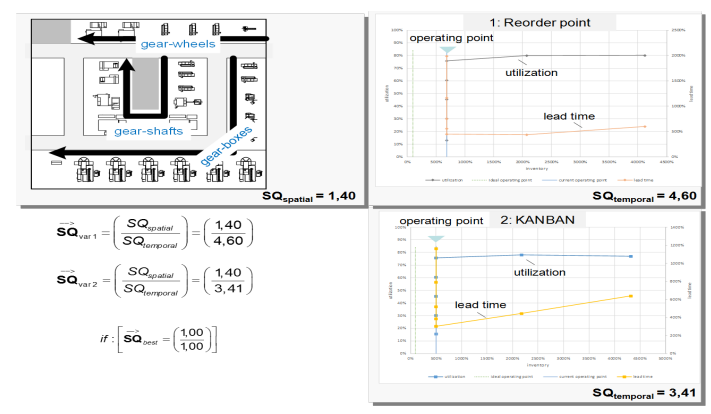

Fig. 2. Structural Quality of a manufacturing system (1: reorder point procedure, 2: kanban)

\subsection{Discussion}

The concrete Structural Quality of both variants depends on the aims of the company. A clear advantage of one of the variants is not assessable due to the fact that vectors for the spatial and the temporal reveal a different tendency. While the numerical value of the spatial vector is decreasing due to the change from a workshop to a line production, the value of the temporal vector is increasing simultaneously. On the contrary, the vector for the temporal quality of the structures reveals that all in all the workshop structure enables a better performance compared to the line structure with reorder point procedure or Kanban principle. However, the Kanban structure reveals a clear advantage compared to the reorder point procedure due to the fact that the inventory inherent in the systems is lower for the Kanban principle. Nevertheless, capacity utilization of the workshop structure is higher than the value of the production lines because of the multi-variant production program. Additionally, the actual operation point of the workshop production is closer to its optimal operation point than the respective operation points of the line production (Figures 1 and 2).

\section{Conclusion and Outlook}

The Structural Quality shall be used to analyze the efficiency that is the temporal and cost-oriented input-output-relation with the idea of minimizing the factor 
input while keeping the output quantity. Under consideration of the companyspecific objectives, the Structural Quality, therefore, provides the potential of an exogenously induced and/or endogenously enabled variation of the production structure. Thus, at this point the Structural Quality facilitates an assessment of a change of the Spatial and Temporal Structure.

As a result, the vectors for the spatial and the temporal Structural Quality changed. This highlights the insight that variations of one of the three system aspects (quantity of elements, interrelations between these elements or characteristics of these elements and interrelations) can lead to shifts regarding both the temporal and the spatial quality of the system structure. Accordingly, this measurable parameter enables verifying the appropriateness of the installed system structure concerning a specific production program in terms of a proper function of the production system.

On the contrary, the Structural Quality can serve as a mean to assess the resilience of a system regarding a changing production program and its impact of the system's configuration. This refers to both the Spatial and the Temporal Structure. The first one indicates the impact of a variation of the production program on the appropriateness of the disposal of resources (layout). The second one relates to attaining objectives (lead time, WIP, utilization) despite changes of the production program.

\section{References}

1. Costanzo, F., Kanda, Y., Kimura, T., Kühnle, H., Lisanti, B., Srai, J.S., Thoben, K.D., Wilhelm, B., Williams, P.M.: Enterprise Organization and Operation. In: Springer Handbook of Mechanical Engineering, pp. 1267-1359. Springer (2009)

2. Ropohl, G.: Allgemeine Technologie: Eine Systemtheorie der Technik. KIT Scientific Publishing (2009)

3. Bokranz, R., Landau, K.: Handbuch Industrial EngineeringProduktivitätsmanagement mit MTM, Band 1 Konzept, 2. Überarbeitete und erweiterte Auflage, Schäffer-Poeschel Verlag, Stuttgart (2012)

4. Kühnle, H., Henn G. Strukturplanung. In Eversheim, W., Schuh G, e.: HütteProduktion und Management "Betriebshütte" 2.2. Springer (1996)

5. Töyli, H.L., Lauri Ojala, J., Wieland, A., Marcus Wallenburg, C.: The Influence of Relational Competencies on Supply Chain Resilience: A Relational View. Int. J. of Physical Distribution \& Logistics Management 43(4), 300-320 (2013)

6. Heinicke, M.: Influence of Shifts in Production Programs on the Resilience of Production Systems. Procedia CIRP 41, 117-122 (2016)

7. Kitano, H.: Biological Robustness. Nature Reviews Genetics 5(11), 826-837 (2004)

8. Francis, R.L., McGinnis, L.F., White, J.A.: Facility Layout and Location: An Analytical Approach. Prentice-Hall (1992)

9. Tompkins, J.A.: Facilities Planning. Hoboken, N.J. Wiley (2010)

10. Hildebrand T, Mäding K, G.U.: Plug + Produce - Gestaltungsstrategien für die Wandlungsfähige Fabrik. IBF. Techn. Univ. Chemnitz (2005)

11. Nyhuis, P., Wiendahl, H.P.: Fundamentals of Production Logistics: Theory, Tools and Applications. Springer (2014) 